\title{
DOES INFLATION TARGETING WORK WELL? EVIDENCE FROM CEE COUNTRIES*
}

\author{
Chen WANG \\ (Received: 28 February 2015; revision received: 10 September 2015; \\ accepted: 15 December 2015)
}

This article examines the effects of inflation targeting (IT) policy on inflation and output performance. I employ the propensity score matching method for the sample of CEE countries from 1990 to 2010 . The evidence suggests that the IT regime does not have a significant effect on the inflation level or the inflation volatility; however, the IT framework can help to increase GDP per capita. The effects on inflation indicators are inconsistent with previous studies. The results are robust to different methodologies.

Keywords: inflation, inflation targeting, CEE countries, propensity score matching

JEL classification indices: E31, E52, E58

\section{INTRODUCTION}

Inflation targeting (IT), as a monetary policy framework, has become popular since the early 1990s. The number of countries that have adopted IT is growing. According to the International Monetary Fund (2010), there were 28 such coun-

* I am greatly indebted to Professor Renée Fry-McKibbin and Dr. Gaurab Ayal for their helpful suggestions and advice. I am also grateful to the two anonymous referees for their comments. All remaining errors are my own.

Chen Wang, PhD candidate at the Research School of Finance (RSFAS), Australian National University, Canberra and Lecturer at the Division of Science and Technology, United International College, Zhuhai, China. E-mail: chen.wang@anu.edu.au 
tries. In addition, a large number of other developed and developing countries are considering a move in this direction (e.g., USA, Japan, and India). Based on the study by Mishkin - Savastano (2001), the IT framework provides a public announcement of a specific numerical inflation target, which is a strong commitment by the monetary authority to price stability as well as to high accountability and to a high degree of transparency. According to Svensson (1997), the most important feature for IT is a "forward-looking decision-making procedure", which is called "inflation-forecast targeting".

Since New Zealand first implemented an IT regime, its advantages and disadvantages continue to be debated in the economic literature (Roger 2009). Gonçalves - Salles (2008) employ cross-section difference-in-difference OLS methods developed by Ball - Sheridan (2005) to test IT effects on inflation as well as on output growth in 36 developing countries. They claim that IT countries have a better performance in lowering the inflation level as well as output growth than in non-IT economies. In accordance with the study of Gonçalves - Salles (2008), Batini - Laxton (2006) provide better results by employing the same cross-section difference-in-difference OLS methods: IT not only helps to lower the inflation level and output growth volatility, but also helps to lower inflation volatility. ${ }^{1}$ Lin - Ye (2009) evaluated 13 developing countries by employing propensity score matching methods to show that IT has a significant effect on lowering the inflation level as well as inflation volatility. Fraga et al. (2003) - by using Brazil as an example - also argue that IT has been successful in developing countries. In accordance with the study of Fraga et al. (2003), Ito - Hayashi (2004) compared IT regimes in four Asian countries and argue that the introduction of IT helps to form a sound monetary policy framework and increases accountability and policy transparency.

By contrast, Taguchi - Kato (2011) found negative impacts. They claim that the difficulty that emerging countries encounter is how to manage the exchange rate impacted by the external debt denominated in US dollars. In theory, IT can be implemented in a floating exchange rate environment. However, Calvo - Reinhart (2002) argue that developing countries have a "fear of floating", which means that they fear the credibility of their own currency. The developing countries' focus on exchange rate volatility restrains them from adopting an IT policy at the first step. As such, small and open economies encounter more fluctuations in exchange rates through the "pass-through" effect, which interferes with the monetary authority's ability to control the inflation level and to implement IT.

Another problem, as Taguchi - Kato (2011) suggest, is that developing economies lack credibility for inflation targeting, which may originate from insufficient

1 Brito - Bystedt (2010) found the same for output growth. 
independence of the monetary authority, economic volatility, or less precise inflation forecasting ability. Hence, if agents do not believe that the monetary authority has the ability to make IT successful, the effect of IT on the behaviour and expectations of the private sector regarding pricing or wage contracts is limited to enervate the strength of IT.

In addition, formal empirical evidence on the IT treatment effect in developed countries is criticised by Gonçalves - Salles (2008), who note that such studies may be plagued with selection bias. On the empirical front, it is not surprising that developed countries that adopted an IT regime did not demonstrate economic gains because such countries either did not suffer serious inflation problems or their macroeconomic condition was stable initially. Hence, insignificant economic gains have been observed. However, it may remain possible to provide benefits to emerging nations that experience larger shocks as well as difficulties in designing effective macroeconomic policies.

The purpose of this paper is to test the IT policy performance by employing specific examples of Central and Eastern European (CEE) countries. This paper is based on Taguchi - Kato (2011), Novák (2014) and Lin - Ye (2009) works. This paper extends the study of European economies conducted by Novák (2014), who examined the exchange and monetary policy framework for Central and Southern European emerging countries; this paper focuses on the inflation targeting policy in CEE emerging and developed economies. The sample afforded the flexibility to use or interpret the results reliably from average treatment effect on treated (ATT) for testing IT policy effects on prices. Second, the sample in this study is much more related to recent periods. Lin - Ye (2009) employed the data from the year 1985 to the year 2005, whereas I extend the periods to the year 2010. Moreover, Lin - Ye (2009) examined the sample through the end of 2004, when most CEE countries had not adopted an IT policy. Such relatively recent periods enable the examination of the financial crisis regarding the IT policy performance in the CEE countries. Third, according to Ball - Sheridan (2005), most previous studies ignore the self-selection problem for policy adoption, and such activity leads to biased estimation results. ${ }^{2}$ More specifically, previous studies employ a difference-in-difference approach (e.g. Neumann - Hagen 2002), and they find a significant decrease in the mean and variance of the inflation level. Nevertheless, their studies ignored the potential problem of endogeneity, which means that the initial inflation level impacted the decision to adopt IT. Thereafter, as Ball - Sheridan (2005) suggested, a study that does not examine the countries' initial condition is more likely to have biased results. Hence, this paper employs propensity score matching techniques to control for the self-selection problem,

Refer to Dehejia - Wahba (2002) and Heckman et al. (1997) for detailed discussions. 
which examines whether macroeconomic factors such as lagged inflation level, lagged GDP growth rate, money growth, trade to GDP ratio, debt to GDP ratio and IT adoption in neighbouring countries have an impact on the countries' decision to adopt IT. ${ }^{3}$ Thus, this study improves the literature by Taguchi - Kato (2011) on examining IT and its influence on the inflation volatility or the inflation level. Fourth, regarding the effects of an IT regime, I simultaneously examine the output indicator (GDP per capita) in addition to inflation indicators, as suggested by Brito - Bystedt (2010).

My findings suggest that the average treatment effect regarding economic output is significant and large within inflation targeting countries. However, inconsistent with previous studies, IT has no significant effects on the inflation level and inflation volatility ${ }^{4}$ in CEE countries. Generally, compared with nonIT countries, an IT regime helps to increase GDP per capita. In addition, I test whether an IT regime works in financial crisis periods (2007-2010 in this study). The evidence shows that even in financial crisis periods, inflation targeting works well with respect to GDP per capita in IT countries.

The remainder of this study is structured as follows. Section 2 presents the data and method used. Section 3 provides the empirical results and discussions. Section 4 describes the robustness tests and extended analysis, and compares these with the propensity score matching method. Section 5 summarises and concludes.

\section{DATA AND EMPIRICAL METHOD}

This study covers 16 economies in the CEE area from 1990 to 2010. Most of the data stems from the IMF World Economic Outlook Databases (WEO) and the World Bank's Economic Policy \& External Debt database. The information on inflation targeting in CEE countries is obtained from the IMF website and the National Bank of Slovakia. In accordance with Ball - Sheridan (2005) and Lin - Ye (2007), I contend that inflation targeting starts to have an effect in the first year after a country has adopted IT. The starting year for each individual IT country is obtained from Roger (2010) and IMF adjustments. The inflation targeters

3 According to Mendonça - de Guimarães (2012), the propensity matching score is by far the best fitted methodology available in the literature to examine the treatment effect of an IT regime. The idea of control variable "IT adoption in neighbouring countries" is that a country is more likely to adopt the IT policy regime if a neighbour country has already implemented the IT framework each year.

$4 \quad$ Measured by the consumer price index (CPI). Inflation volatility is defined as the standard deviation for the moving average of the inflation level (CPI) in the next three years. 
and their IT adoption years are: Czech Republic (1997), Poland (1998), Hungary (2001), Romania (2005), Serbia (2006), Slovakia (2005), and Albania (2009). The non-inflation targeters are Bosnia and Herzegovina, Bulgaria, Croatia, Estonia, Latvia, Lithuania, Macedonia, Montenegro, and Slovenia.

\subsection{Treatment effect and selection bias}

The objective of the paper is to test and compare the average treatment effect between IT countries and non-IT nations. Hence, to test the ATT (average treatment effect on the treated group), the following equation is employed:

$$
A T T=E\left[Y_{i 1} \mid D_{i}=1\right]-E\left[Y_{i 0} \mid D_{i}=1\right]
$$

where $D$ is a dummy variable (if a country adopts IT, $D$ equals 1 , otherwise $D$ is $0), Y$ is the outcome (inflation level, inflation volatility, and GDP per capita, in this case), $Y_{i 0} \mid D_{i}=1$ denotes the result if an inflation targeting country has not implemented an IT policy, $Y_{i 1} \mid D_{i}=1$ and is the outcome observed in reality for the same country that adopted IT. The difficulty is that the second item on the right hand side of the equation is not observable because it is not possible to observe the outcome in a targeting country that has not adopted IT. If inflation targeting is randomly adopted, we can calculate the average treatment effect easily by comparing the mean in the treatment group (in this case, IT countries are in the treatment group) with that in the control group (non-IT countries in this case). But biased results will be observed if targeting policy adoption is not randomly selected. According to Dehejia - Wahba (2002), if observable variables, which are correlated with inflation targeting adoption, also impact the outcomes, a selection of observable variable problems will be raised; as such, the traditional linear regression models are unreliable.

\subsection{Propensity score matching methods}

According to Dehejia - Wahba (2002), propensity score matching techniques should be implemented to solve the problem of the "selection of unobserved observations". To conduct the test, it is important to conduct a randomised experiment with a control group, and then to compare the results with a treatment group. The assumption (which is called the unconfoundedness hypothesis) needed for the propensity score matching method is to make outcomes independent 
with the IT dummy variable, given a condition on $\left(Y_{0}, Y_{1} \perp D \mid X\right) .{ }^{5}$ According to Heckman et al. (1997), to estimate ATT, we can use a weaker assumption of mean independence: ${ }^{6}$

$E\left[Y_{i 0} \mid D_{i}=1, X_{i}\right]=E\left[Y_{i 0} \mid D_{i}=0, X_{i}\right]=E\left[Y_{i 0} \mid X_{i}\right]$, which requires the outcomes (inflation level and inflation variability) to be independent of inflation targeting adoption. Hence, equation (1) can be expressed as:

$$
A T T=E\left[Y_{i 1} \mid D_{i}=1, X_{i}\right]-E\left[Y_{i 0} \mid D_{i}=0, X_{i}\right]
$$

Hereafter, the second term on the right is observable.

According to equation (2), one can use the matching method to match the treated group with the control group for similar values of $X$. However, when the number of covariates in $X$ increases, this method becomes difficult to conduct in practice. To solve such a high volume problem, Rosenbaum - Rubin (1983) proposed a method in which one can match the treated group with control groups on their propensity scores (in this case, the probability for policy adoption with conditioning on $X$ ), which can be estimated by probit or logit models (in this paper, I employ the logit model). According to Heckman et al. (1997), to make the equation well-defined simultaneously for all $X$, it is usually assumed that $0<\mathrm{P}(X)$ $<1$; this requires the existence of both comparable treated units for each control unit and comparable control units for each treated unit. The proofs are shown in their paper.

Hence, with the propensity matching score method, equation (2) can be rewritten as:

$$
A T T=E\left[Y_{i 1} \mid D_{i}=1, p\left(X_{i}\right)\right]-E\left[Y_{i 0} \mid D_{i}=0, p\left(X_{i}\right)\right] .
$$

Although the propensity matching score is the best fitted methodology available in the literature thus far to examine the treatment effect of an IT regime (Mendonça - de Guimarães 2012), and many empirical studies employed PSM to examine the treatment effect for inflation targeting (e.g., Lin - Ye 2007, 2009), there remain certain common disadvantages, namely an unconfoundedness hypothesis problem. That is, the unconfoundedness hypothesis, which assumes

5 According to Lin - Ye (2007), under the conditional independence assumption, the average treatment effect (ATE) equals the average treatment effect on the treated (ATT).

6 A weaker assumption means we assume that $Y_{(i 0)}$ is independent with $\mathrm{D}$, compared with a stronger assumption that both $Y_{(i 0)}$ and $Y_{(i 1)}$ are independent with D. 
$\left(Y_{0}, Y_{1} \perp D \mid X\right)$, cannot be tested in practice. This remains a task for future research.

According to Heckman et al. (1997), four different methods of propensity score matching will be used in this study: nearest neighbour matching, radius matching, kernel matching, and stratification matching. These are explained by Becker - Ichino (2002).

\section{EMPIRICAL TESTS FOR AVERAGE TREATMENT EFFECTS}

This section examines the IT regimes' average treatment effects on the level of inflation, which is measured by the consumer price index (CPI), the inflation volatility, which is the standard deviation for the moving average of inflation over the next three years, and the GDP per capita (Figure 1). Average inflation level is calculated for IT and non-IT countries separately for each year. For example, in 1997, the average inflation level for IT countries is the mean of CPI for all IT countries in 1997. In 1997, the average inflation level for non-IT countries is the mean of CPI for all non-IT countries in 1997. A similar method applies to the average inflation volatility and the GDP per capita. Clear, similar trends for the average inflation level, the average inflation volatility, and the average GDP per capita are shown in the figure for both IT and non-IT countries. Hence, previous studies (i.e., Taguchi - Kato 2011) argue that the significant difference before and after adopting an IT policy may imply a wrong conclusion regarding an inflation targeting effect. For example, during the 1998 to 2001 period, we can observe a significant reduction trend for inflation volatility in the IT group when many CEE countries began to adopt an IT regime; however, such a decreasing trend may not be caused by the newly adopted IT regime, but instead be caused by certain common factors, which have an impact on both targeting and non-targeting countries.

\subsection{Empirical estimation of the propensity scores}

To examine the propensity scores, a logit model is chosen in which the dependent variable is a dummy (for inflation targeting countries, the dummy equals 1 , and for countries never experiencing an inflation targeting framework, the dummy equals 0 ). Based on the previous literature regarding IT adoption choices (for 


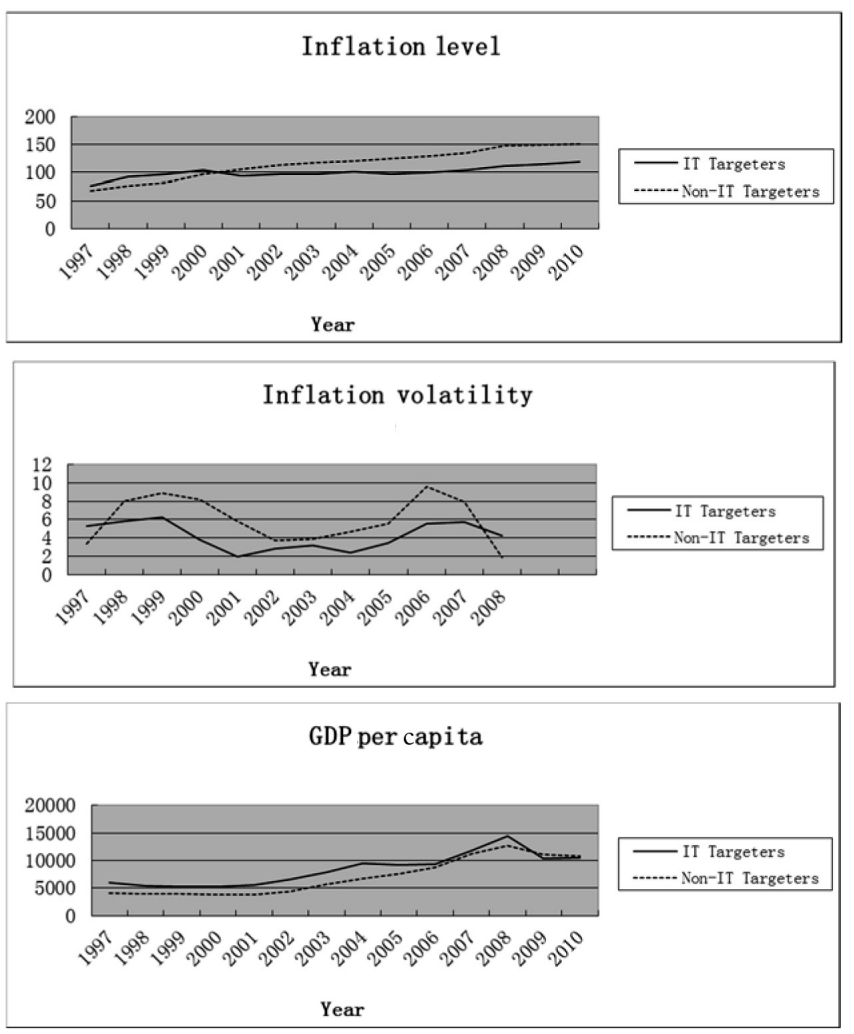

Figure 1. Average inflation level, average inflation volatility, and average GDP per capita in IT and non-IT countries

example, Mishkin 2004), ${ }^{7}$ I employ three independent variables of interest: money growth (measured as the average annual growth rate in money and quasi-money, which is expected to negatively correlate with IT adoption), the lagged inflation level (the CPI level in the previous year, which is expected to positively correlate with IT adoption), and the lagged GDP growth rate (the GDP growth rate in the previous year, which is expected to positively relate with an IT framework adoption). Other variables are employed in the model to control for the open status of

7 The goal of the propensity score matching is not to find a perfect model to explain the probability of IT adoption. Because of the conditional independence assumption, the exclusion of some variables which systematically impact on IT adoption, but not on the inflation level (or GDP per capita results) will not harm the tests. Instead, it will help the unconfoundedness hypothesis assumption to be satisfied. For more details, see Lin - Ye (2007). 
Table 1. Propensity scores estimated by the logit model

\begin{tabular}{l|c|c|c|c|c|c}
\hline \hline & $\begin{array}{c}\text { Baseline } \\
\text { model }\end{array}$ & $\begin{array}{c}\text { No hyper- } \\
\text { inflation }\end{array}$ & Post-2000 & $\begin{array}{c}\text { Financial } \\
\text { crisis }\end{array}$ & $\begin{array}{c}\text { Adding } \\
\text { DEBTGDP }\end{array}$ & $\begin{array}{c}\text { Adding } \\
\text { Neighbour- } \\
\text { IT-Adop- } \\
\text { tion }\end{array}$ \\
\hline & & model & sample & sample & model & model \\
\hline Lag Inflation & 0.017 & 0.017 & -0.006 & -0.058 & 0.012 & -0.002 \\
\hline $\begin{array}{l}\text { Lag GDP } \\
\text { growth }\end{array}$ & 0.101 & 0.101 & 0.054 & 0.062 & 0.096 & 0.095 \\
\hline Money growth & -0.031 & -0.031 & -0.028 & -0.012 & -0.032 & -0.045 \\
\hline Open & 0.013 & 0.013 & 0.008 & -0.007 & 0.007 & 0.014 \\
\hline Ln Population & $4.479^{* * *}$ & $4.468^{* * *}$ & $4.018^{* * *}$ & $3.905^{* * *}$ & $4.317^{* * *}$ & $5.077^{* * *}$ \\
\hline DEBTGDP & & & & & 0.038 & \\
\hline $\begin{array}{l}\text { Neighbour-IT- } \\
\text { Adoption }\end{array}$ & & & & & & 1.58 \\
\hline Constant & $-11.363^{* * *}$ & $-11.39^{* * *}$ & $-7.454^{* *}$ & -0.017 & $-11.232^{* * * *}$ & $-11.326^{* * *}$ \\
\hline $\begin{array}{l}\text { No. of } \\
\text { observations }\end{array}$ & 174 & 166 & 126 & 56 & 150 & 168 \\
\hline Pseudo R2 & 0.69 & 0.68 & 0.65 & 0.6 & 0.7 & 0.68 \\
\hline
\end{tabular}

Notes: The dependent variable is a dummy. If a country adopts IT in a given year, the dummy equals 1 for the observation in that given year. If a country never adopts IT, the country is in the control group and the dummy equals 0 . The "No hyperinflation model" excludes the observation experiencing a serious hyperinflation problem with annual inflation rates of more than $50 \%{ }^{*}, * *$, and $* * *$ indicate the significance level of $10 \%, 5 \%$, and $1 \%$, respectively.

the country (measured by the trade to GDP ratio, which is expected to positively relate to IT regime adoption), the natural $\log$ of the population of the country (which is expected to be positively related with IT adoption), the debt to GDP ratio (which is expected to be positively related with IT adoption) as well as the IT adoption dummy for the neighbouring country (the dummy equals 1 if a neighbouring country has previously adopted the IT regime in a given year, otherwise it equals 0 , which is expected to be positively correlated with IT adoption). The logit regression model results are reported in Table 1, where each control variable in the model is explained above.

Although most coefficients estimated from the model are not significant according to the t-test at the $5 \%$ significance level, all of the signs of the coefficients are consistent with expectations, and the natural log of population is found to be significant and positively related to IT adoption (at the $1 \%$ level). This is an interesting result that previous studies did not display. The coefficient (4.479) implies that for an increase in one unit of the natural log of population, the odds $(\mathrm{p} /(1-\mathrm{p})$ will increase 88.146 , where $p$ is the probability that the country will adopt an IT policy. The Broad Money factor as well as the openness (trade to GDP ratio) factor are found to be insignificantly correlated to the IT policy (at the 5\% sig- 
nificance level), which is different from previous studies (I find that the pseudoR-square is approximately 0.69 , which is much higher than the 0.22 in Lin - Ye 2007). The evidence shows that except for the population factor, virtually none of the macroeconomic conditions of a country determine whether a central bank will choose to adopt the IT framework within the CEE area.

The estimation results for additional robustness tests are explained in the "Robustness Checks" section.

\subsection{Empirical estimating for the matching results}

The results for treatment effects estimated by the propensity score matching method are illustrated in Tables 2, 3 and 4, which reflect ATT on the inflation level, the inflation volatility, and GDP per capita, respectively.

In each table, the first column reports nearest neighbour matching results. Then, in the next three columns, I report the radius matching results with a radius of $0.01,0.02$, and 0.03 , respectively. In the last two columns, I report the results of kernel matching and stratification matching.

Table 2 shows that in the baseline model, the average treatment effect of inflation targeting on the inflation level estimated by the four matching methods is on average 6.5 lower for treatment group observations, which means that the CPI is (on average) 6.5 lower in IT countries compared with that in non-IT countries. However, such effects are not significant, even at the $10 \%$ significance level. The evidence shows that the IT framework does not work well on reducing (or increasing) inflation level, which is at variance with previous studies on emerging or developed economies.

The baseline in Table 3 illustrates that the average treatment effect of IT on inflation volatility estimated by different matching techniques is -1.241 , which means that the standard deviation of CPI in the next three years is 1.241 lower in IT countries compared with their peers without IT policy. Hence, it appears that IT can help to decrease the inflation volatility; however, such an effect is found to not be as significant as other previous literature suggested.

Table 4 provides estimation results for the treatment effects of an IT regime on GDP per capita. The results show that the treatment effects for GDP per capita are relatively positive and significant for the kernel matching method (significant at the $5 \%$ level) and the stratification matching method (significant at the $1 \%$ level). The average treatment effect estimated by the four matching methods is $2,143.236$, which means that on average, if a country adopts an IT framework, 
Table 2. Estimates of the treatment effect on inflation level

\begin{tabular}{l|c|c|c|c|c|c}
\hline \hline & \multicolumn{7}{c}{ Matching Methods } \\
\cline { 2 - 8 } & $\begin{array}{c}\text { Nearest } \\
\text { neighbour }\end{array}$ & \multicolumn{2}{c}{ Radius matching } & $\begin{array}{c}\text { Kernel } \\
\text { matching }\end{array}$ & $\begin{array}{c}\text { Strati- } \\
\text { fication } \\
\text { matching }\end{array}$ \\
& matching & $\mathrm{r}=0.01$ & $\mathrm{r}=0.02$ & $\mathrm{r}=0.03$ & & \\
\hline $\begin{array}{l}\text { Baseline model } \\
\text { No hyperinflation } \\
\text { model }\end{array}$ & -11.934 & 4.005 & -2.853 & -3.97 & -7.322 & -16.936 \\
\cline { 2 - 8 } $\begin{array}{l}\text { Post-2000 sample } \\
\text { Financial crisis sample }\end{array}$ & -11.698 & 8.395 & -4.920 & -6.823 & -8.134 & -17.598 \\
\cline { 2 - 8 } $\begin{array}{l}\text { Adding DEBTGDP } \\
\text { model }\end{array}$ & -3.343 & -2.717 & 2.267 & 0.47 & -2.518 & -1.692 \\
\hline $\begin{array}{l}\text { Adding Neighbour-IT- } \\
\text { Adoption model }\end{array}$ & -12.711 & -8.774 & -8.229 & -9.665 & $-20.776^{* *}$ & -5.656 \\
\hline
\end{tabular}

Notes: The "post-2000 sample" examines the effects for the observations after 2000. The "Financial crisis sample" investigates the observations between 2007-2010. "Adding DEBTGDP model" is the model with a control variable "debt to GDP ratio" added to the baseline model. "Adding Neighbour-IT-Adoption model" is the model with a control variable "Neighbour-IT-Adoption" added to the baseline model. The Epanechnikov kernel and " 0.05 " as fixed bandwidth are used for kernel matching. Bootstrapped t-statistics are based on 500 replications of the data. *,*, and *** indicate the significance level of $10 \%, 5 \%$, and $1 \%$, respectively.

Table 3. Estimates of the treatment effect on inflation volatility

\begin{tabular}{l|c|c|c|c|c|c}
\hline \hline & \multicolumn{7}{c}{ Matching Methods } \\
\cline { 2 - 8 } & $\begin{array}{c}\text { Nearest } \\
\text { neighbour } \\
\text { matching }\end{array}$ & \multicolumn{2}{c}{ Radius matching } & \multicolumn{2}{c}{$\begin{array}{c}\text { Kernel } \\
\text { matching }\end{array}$} & $\begin{array}{c}\text { Stratification } \\
\text { matching }\end{array}$ \\
\hline Baseline model & -1.389 & -1.184 & -1.207 & -2.071 & -1.033 & -0.562 \\
\cline { 2 - 8 } $\begin{array}{l}\text { No hyperinflation episodes } \\
\text { Post-2000 sample }\end{array}$ & -1.338 & -0.367 & -1.383 & -2.078 & -0.959 & -0.712 \\
\cline { 2 - 8 } $\begin{array}{l}\text { Financial crisis sample } \\
\text { Adding DEBTGDP }\end{array}$ & -0.852 & -3.88 & $-3.138^{*}$ & -2.582 & -2.476 & -1.14 \\
\cline { 2 - 8 } & $-4.964^{* *}$ & -8.869 & -3.053 & -1.858 & -2.403 & -2.381 \\
\hline $\begin{array}{l}\text { Adding Neighbour-IT- } \\
\text { Adoption model }\end{array}$ & -1.267 & -1.515 & -1.075 & -1.29 & -0.86 & -0.56 \\
\hline
\end{tabular}

Notes: see Table 2. 
Table 4. Estimates of the treatment effect on output (GDP per capita)

\begin{tabular}{|c|c|c|c|c|c|c|}
\hline & \multicolumn{6}{|c|}{ Matching Methods } \\
\hline & \multirow{2}{*}{$\begin{array}{c}\text { Nearest } \\
\text { neighbour } \\
\text { matching }\end{array}$} & \multicolumn{3}{|c|}{ Radius matching } & \multirow{3}{*}{$\begin{array}{c}\begin{array}{c}\text { Kernel } \\
\text { matching }\end{array} \\
3,547.436^{* *}\end{array}$} & \multirow{3}{*}{$\begin{array}{c}\begin{array}{c}\text { Stratification } \\
\text { matching }\end{array} \\
3,149.144^{* * *}\end{array}$} \\
\hline & & $\mathrm{r}=0.01$ & $\mathrm{r}=0.02$ & $\mathrm{r}=0.03$ & & \\
\hline Baseline model & $3,008.584$ & 212.114 & $2,580.917$ & $2,771.33$ & & \\
\hline $\begin{array}{l}\text { No hyperinflation } \\
\text { episodes }\end{array}$ & $2,998.304$ & $1,397.811$ & $2,356.676$ & $2,586.506$ & $3,497.522 * *$ & $3,182.469 * * *$ \\
\hline Post-2000 sample & $8,620.33 * * *$ & $-2,363.697$ & 229.075 & $4,965.26$ & $3,101.458$ & $7,229.499 * *$ \\
\hline $\begin{array}{l}\text { Financial crisis } \\
\text { sample }\end{array}$ & $4,550.691 *$ & $-8,163.189$ & $-4,234.751$ & $-2,019.24$ & $-3,057.572$ & -692.282 \\
\hline Adding DEBTGDP & $7,112.883^{* * *}$ & 43.029 & $3,770.103$ & $5,502.044 *$ & $6,949.195 * *$ & $6,609.418^{* * *}$ \\
\hline $\begin{array}{l}\text { Adding Neighbour- } \\
\text { IT-Adoption model }\end{array}$ & $3,993.567 * * *$ & $3,910.987 *$ & $5,823.599 * * *$ & $5,326.828 * * *$ & $5,393.044 * * *$ & $4,704.188 * * *$ \\
\hline
\end{tabular}

Notes: see Table 2.

this will help the nation to increase GDP per capita by USD 2,143.236 in that year. Such significant effects are very noticeable and can be considered by the policymakers in the CEE regions.

\section{ROBUSTNESS CHECKS}

Because certain economies of the covered 16 economies in the CEE area experienced serious hyperinflation problems, with annual inflation rates of more than $50 \%$, it may be suspected that the results may be driven by such extreme inflation values. Thus, it is necessary to eliminate such hyperinflation units. The new results regarding estimated propensity scores are shown in the second column in Table 1. The results are similar to those in the first column of the table used in Section 3. The coefficients for the lag of inflation, the lag GDP growth rate, and the trade to GDP ratio are positive and insignificant, whereas the coefficient for money growth is negative and insignificant. The new ATT results when controlling for hyperinflation are illustrated in the second row of Tables 3, 4, and 5 . The new ATT estimated by the four matching method is negative $(-6.796)$ but insignificant (even at the $10 \%$ significance level) in terms of the inflation level. The estimated ATT on inflation variability is approximately -1.14 (by the four matching methods); however, the results are insignificant. The average treatment effect on GDP per capita is USD 2,335 (which means that the IT countries have USD 2,335 compared with those never experiencing an inflation targeting 
policy); the results are significant with the kernel matching method (at the 5\% significance level) and the stratification matching method (at the $1 \%$ significance level). Generally, the results on the inflation level and the inflation volatility are insignificant, which are at variance with the previous literature. Similarly to the baseline model, the ATT of GDP per capita remains positive when controlling for hyperinflation problems. All of the results show that the average treatment effects are not much influenced by the extreme inflation values within CEE countries.

To check whether the average treatment effect is robust to different time periods, the post-2000 samples are examined using propensity score matching methods. ${ }^{8}$ The results are displayed in column 3 in Table 1 using logit model regression. The results provide very similar coefficients compared with the above tests; solely the coefficient on the natural log of population is significantly positive, and the Pseudo $\mathrm{R}^{2}$ is 0.65 . The estimation of ATT results on the inflation level, the inflation volatility, and the GDP per capita are reported in the third rows of Tables 3, 4, and 5. The evidence shows that the ATT on the inflation level is insignificant, whereas the IT effect on inflation volatility is negative. In addition, the radius matching method shows a significant (at the 10\% level) result (ATT equals -3.138 ) when the radius equals 0.02 , which means that the CPI standard deviation for the next three years is 3.138 lower in IT countries compared with non-IT countries. However, such significant results do not hold for all other matching methods, which imply that this significant result may not be catholic. The ATTs for GDP per capita still display positively large and significant results when employing nearest neighbour matching or stratification matching methods.

The ability of the monetary policy framework to respond effectively to financial crises and economic downturns, and the optimal form that monetary policy framework should take has again become topical since the 2007 financial crisis episode. Therefore, my third test is to examine whether the results are robust to financial crisis periods. ${ }^{9}$ The logit model estimating the propensity score is displayed in the fourth column in Table 1 . The results show that the explanatory power has decreased (because the Pseudo $\mathrm{R}^{2}$ decreased to 0.6 ); solely the natural $\log$ of population is found to be significant (at the $1 \%$ significance level). Additionally, the ATT results are reported in the fourth rows in Tables 3, 4, and 5. However, we can still find coefficient results similar to the above section (which

8 According to Lin - Ye (2009), the time periods after the year 2000 may have different effects compared with the observations before 2000 . Hence, it is reasonable to test the results separately in different time periods.

9 Referring to Pathan - Faff (2013), economic outcomes may be different in financial crisis periods and thus they need to be examined separately. In this paper, I employ the period from 2007-2010 as the financial crisis period. 
means that inflation targeting continues to help to increase GDP per capita, and the results on lowering inflation level as well as inflation volatility are insignificant). The exception is the inflation volatility result estimated by the nearest neighbour matching method, which is significant at the $5 \%$ level (the coefficient is -4.964 , which means that the standard deviation for CPI in the next three years is 4.964 lower compared with non-IT countries). However, such effects disappear for all of the other estimation methods; this means that the significant results may not be prevalent. Hence, in financial crisis periods, inflation targeting still works with respect to GDP per capita with nearest neighbor matching method.

Last, I will check whether the ATT effect will be sensitive to alternative specifications of the logit model. Therefore, the debt to GDP ratio (DEBT-GDP) ${ }^{10}$ and Neighbour-IT-Adoption ${ }^{11}$ is added to the logit model; the results for the logit model are displayed in the fifth and sixth columns in Table 1. The results show that both debt to GDP ratio and Neighbour-IT-Adoption will positively impact on the IT adoption decision; however, such effects are observed to be insignificant. One more interesting finding, which is not observed by Lin - Ye (2009), is that the Pseudo $\mathrm{R}^{2}$ increased to its peak of 0.7 when debt to GDP ratio is included in the regression. This suggests that the IT adoption regression model can be improved if the DEBT-GDP factor is included. According to the fifth and sixth rows in Tables 3, 4, and 5, most ATT effects remain similar to previous results, which is that IT improves the GDP per capita significantly; however, the results for the inflation indicators are not obvious. The sole exception is that the ATT effect on the inflation level estimated by the kernel matching method is significant at the $5 \%$ level (the coefficient is -20.776 , which means that the average CPI is 20.776 in IT countries compared with that in non-IT nations); however, such effects do not hold for all of the other estimation techniques.

In sum, the evidence shows a strong and consistent result after the robustness checks. Inflation targeting works well on increasing the GDP per capita for a country; however, it appears to be ineffective with respect to lower inflation level or inflation volatility.

10 According to Lin - Ye (2009), when the debt to GDP ratio is added to the model, the estimation results may be different from the model without the debt to the GDP variable. Hence, it is important to test the results if the new control variable "debt to GDP" is included in the model.

11 The idea for Neighbour-IT-Adoption is that a country may be likely to follow the inflation targeting regime if a neighbouring country has previously adopted the IT framework in a given year. 


\section{DISCUSSIONS ON TESTS OF HETEROGENEITY PROBLEMS OF TREATMENT EFFECTS}

According to Carare - Stone (2006), countries in one region may be different from other economies in other regions because they display variety ranges of economic and institutional traits. It is claimed that an inflation targeting policy is influenced by such traits. Thus, it is very important to examine the effectiveness of the heterogeneity feature on the adoption of inflation targeting within CEE countries.

In this section, we examine several possible heterogeneity features using a control function regression method. The first feature is to test whether estimated propensity scores will impact on the inflation level, which means that if countries achieve better preconditions to adopt IT, they will influence the inflation level (or the inflation volatility, or the GDP per capita). Next, because of the time lag influence of adopting IT on the inflation level, we examine whether the time since the country first implemented IT will have an impact on the outcomes of interest. Last, a feature of the government fiscal position will be examined with respect to its effectiveness on inflation indicators and outputs.

The regression results of the heterogeneity effect are reported in Table $5,^{12}$ using a control function regression approach. The OLS regression of the inflation level on the dummy variable of targeting is displayed in the first column in Table 5. This regression result shows that the coefficient of the targeting dummy is observed to be positive, which means that a country that adopts the IT regime has an impact on the increasing inflation level compared with a non-IT country (however, such an effect is not significant). In the second column, I add the control function of the propensity score, which is derived from the logit model in previous baseline test. The coefficient for the targeting dummy variable as well as the p-score continue to be observed as non-significant compared with the previous examination.

In addition to the p-score heterogeneity feature, an interaction term (difference between the propensity score and its average score, as well as the IT dummy variable) is examined to verify treatment effects. According to Lin - Ye (2009), a significant coefficient for the interaction term is the evidence of heterogeneity. The results are reported in the third column of Table 5. Interestingly, the interaction term is observed to be positively correlated with the inflation level; however, such an effect is not significant, which means that the treatment effect is not significant, and no heterogeneity is found in this case.

12 The heterogeneity problems in the studies for inflation volatility and GDP per capita are similar to the study for inflation level. The results are not reported, but can be provided if requested. 
Table 5. Exploring heterogeneity in the treatment effect on level of inflation

\begin{tabular}{l|c|c|c|c|c}
\hline \hline & 1 & 2 & 3 & 4 & 5 \\
\hline IT & 3.401 & -0.629 & -1.205 & & 10.364 \\
\hline PS & & 3.934 & 2.306 & 0.73 & -9.066 \\
\hline IT*(PS-E(PS)) & & & 3.71 & & \\
\hline IT*TIME & & & & $3.622^{* * *}$ & \\
\hline DEBTGDP & & & & & $0.744^{*}$ \\
\hline IT*DEBTGDP & & & & & -0.605 \\
\hline Constant & $100.564 * * *$ & $101.381^{* * *}$ & $101.516^{* * *}$ & $1.841^{* * *}$ & $95.589 * * *$ \\
\hline No. of observations & 206 & 174 & 174 & 57 & 150 \\
\hline $\mathrm{R}^{2}$ & 0.0006 & 0.0006 & 0.0006 & 0.34 & 0.03 \\
\hline
\end{tabular}

Notes: The dependent variable is inflation level. Column 1 reports the model only including "IT" dummy as the control variable. Column 2 reports the model including "IT" and "Propensity score" (estimated by the baseline model from Section 2) as control variables. Column 3 reports the model including "IT", "Propensity score", and an interaction term (difference between propensity score and its average score, as well as IT dummy variable) as control variables. Column 4 reports the model including "Propensity score" and an interaction term (IT dummy as well as Time lag since the country initially adopted IT regime) as control variables. Column 5 reports the IT dummy, propensity score, debt to GDP ratio as well as an interaction (IT dummy as well as debt to GDP ratio) as control variables. The estimation results are obtained by Ordinary Least Square method which includes the constant term. * ,**, and *** indicate the significance level of $10 \%, 5 \%$, and $1 \%$, respectively.

Next, it is necessary to investigate whether the time lag after the IT adoption will influence the inflation level. The fourth column reports the estimation results that the interaction term of IT adoption and time lag since IT adoption do impact the nation's CPI. The coefficient is 3.622 (at the 1\% significance level), which means that the inflation level will increase as time passes (after IT adoption).

Last, to investigate the heterogeneity feature with respect to the fiscal character, the debt to GDP and its product of the targeting dummy variable are added to the model. The result reported in the fifth column shows that the variable debt to GDP ratio can positively impact the consumer price index, which means that more debt in the GDP ratio will lead to an increase in the inflation level. The interaction term between IT and debt to GDP ratio is found to be insignificant to the inflation level.

\section{CONCLUSION}

In this study, I evaluated the average treatment effect of the inflation targeting framework in Central and Eastern European countries that adopted these IT regimes through 2010. Based on the propensity matching score method, I found that the average treatment effects regarding economic output (GDP per capita) are significant and large within inflation targeting countries. Nevertheless, no 
significant effects can be obtained with respect to the inflation level and the inflation volatility.

Generally, both the governments and the central banks within the CEE area (and possibly in other developing countries) need to evaluate their choice of inflation targeting regime by considering the trade-offs between the significant increase in the GDP per capita and the non-significant inflation indicator effects during the normal and financial crisis periods.

\section{REFERENCES}

Ball, L. - Sheridan, N. (2005): Does Inflation Targeting Matter? In: Bernanke, B. S. - Woodford, M. (eds): The Inflation-Targeting Debate. University of Chicago Press, 249-276.

Batini, N. - Laxton, D. (2006): Under What Conditions can Inflation Targeting be Adopted? The Experience of Emerging Markets. Central Bank of Chile Working Papers, No. 406.

Becker, S. O. - Ichino, A. (2002): Estimation of Average Treatment Effects Based on Propensity Scores. The Stata Journal, 2(4): 358-377.

Bernanke, B. S. - Mishkin, F. S. (1997): Inflation Targeting: A New Framework For Monetary Policy? Journal of Economic Perspectives, 11(2): 97-116.

Brito, R. D. - Bystedt, B. (2010): Inflation Targeting in Emerging Economies: Panel Evidence. Journal of Development Economics, 91(2): 198-210.

Calvo, G. - Reinhart, C. (2002): Fear of Floating. Quarterly Journal of Economics, 117(2): 379408.

Carare, A. - Stone, M. (2006): Inflation Targeting Regimes. European Economic Review, 50(5): $1297-1315$.

Ciżkowicz, P. - Rzońca, A. (2015): Inflation Targeting and its Discontents: The Case of Poland. Acta Oeconomica, 65(Spec. iusse 1): 109-124.

Dehejia, R. H. - Wahba, S.(2002): Propensity Score-Matching Methods for Nonexperimental Causal Studies. Review of Economics and Statistics, 84(1): 151-161.

Fraga, A. - Goldfajn, I. - Minella, A.(2003): Inflation Targeting in Emerging Market Economies. NBER Working Papers, 10019.

Gonçalves, C. - Salles, J. (2008): Inflation Targeting in Emerging Economies: What do the Data Say? Journal of Development Economics, 85(12): 312-318.

Heckman, J. - Ichimura, H. - Todd, E. (1997): Matching as an Econometric Evaluation Estimator. Review of Economic Studies, 64(4): 261-294.

IMF (2010): Inflation Targeting: Holding the Line. Retrieved from http://www.imf.org/external/ pubs/ft/fandd/basics/target.htm

Ito, T. - Hayashi, T. (2004): Inflation Targeting in Asia. Hong Kong Institute for Monetary Research Occasional Paper, No. 1, March.

Lin, S. -Ye, H. (2007): Does Inflation Targeting Really Make a Difference? Evaluating the Treatment Effect of Inflation Targeting in Seven Industrial Countries. Journal of Monetary Economics, 54(8): 2521-2533.

Lin,S. -Ye, H. (2009): Does Inflation Targeting Make a Difference in Developing Countries? Journal of Development Economics, 89(1): 118-123

Mendonça, H. F. - Guimarães e Souza, G. J. de (2012): Is Inflation Targeting a Good Remedy to Control Inflation? Journal of Development Economics, 98(2): 178-191. 
Mishkin, F. S. (2004): Can Inflation Targeting Work in Emerging Market Countries? NBER Working Papers, 10646.

Mishkin, F. S. - Savastano, M. (2001): Monetary Policy Strategies for Latin America. Journal of Development Economics, 66(2): 415-44.

Neumann, M. J. - Hagen, J. (2002): Does Inflation Targeting Matter? Federal Reserve Bank of St. Louis Review, 84(4): 127-148.

Novák, Z. (2014): Monetáris politika, infláció és gazdasági növekedés Kelet-Közép és DélkeletEurópában (Monetary Policy, Inflation and Economic Growth in CEE Countries). Közgazdasági Szemle, 61(7-8): 923-942.

Pathan, S. - Faff, R. (2013): Does Board Structure in Banks Really Affect Their Performance? Journal of Banking and Finance, 37(5): 1573-1589.

Roger, S. (2009): Inflation Targeting at 20: Achievements and Challenges. IMF Working Paper, No. $09 / 236$.

Roger, S. (2010): Inflation Targeting Turns 20. Finance \& Development, 47(1): 46-49.

Rose, A. K. (2007): A Stable International Monetary System Emerges: Inflation Targeting is Bretton Woods, Reversed. Journal of International Money and Finance, 26(5): 663-681.

Rosenbaum, R. - Rubin, B. (1983): The Central Role of the Propensity Score in Observational Studies for Causal Effects. Biometrika, 70(1): 41-55.

Svensson, L. (1997): Inflation Forecast Targeting: Implementing and Monitoring Inflation Targets. European Economic Review, 41(6): 1111-1146.

Taguchi, H. - Kato, C.(2011): Assessing the Performance of Inflation Targeting in East Asian Economies. Asian-Pacific Economic Literature, 25(1): 93-102. 